\title{
Fibroblast growth factor 23-Klotho and hypertension: experimental and clinical mechanisms
}

\author{
Michael Freundlich ${ }^{1}$ (D) $\cdot$ Gerardo Gamba ${ }^{2,3} \cdot$ Bernardo Rodriguez-Iturbe $^{3,4}$ \\ Received: 1 May 2020 / Revised: 7 October 2020 / Accepted: 23 October 2020 / Published online: 23 November 2020 \\ (C) IPNA 2020
}

\begin{abstract}
Hypertension (HTN) and chronic kidney disease (CKD) are increasingly recognized in pediatric patients and represent risk factors for cardiovascular morbidity and mortality later in life. In CKD, enhanced tubular sodium reabsorption is a leading cause of HTN due to augmented extracellular fluid volume expansion. The renin-angiotensin-aldosterone system (RAAS) upregulates various tubular sodium cotransporters that are also targets of the hormone fibroblast growth factor 23 (FGF23) and its co-receptor Klotho. FGF23 inhibits the activation of 1,25-dihydroxyvitamin D that is a potent suppressor of renin biosynthesis. Here we review the complex interactions and disturbances of the FGF23-Klotho axis, vitamin D, and the RAAS relevant to blood pressure regulation and discuss the therapeutic strategies aimed at mitigating their pathophysiologic contributions to HTN.
\end{abstract}

Keywords Blood pressure · Tubular sodium handling · Angiotensin · Vitamin D · FGF23

\section{Introduction}

Chronic kidney disease (CKD) and its associated cardiovascular (CV) complications are increasingly prevalent in children [1]. Global prevalence of hypertension (HTN) in the general pediatric population has increased over the last 2 decades [2] and in children with CKD the prevalence of HTN ranges between 24 and $47 \%$ [3]. Clinical observations have described associations between higher blood pressure (BP) and fibroblast growth factor 23 (FGF23) levels, and experimental investigations have shown direct participation of FGF23 and its cofactor Klotho in the pathogenesis of HTN, although the results have not been consistent. Furthermore, higher FGF23 concentrations are strongly associated with higher left ventricular mass independently of BP and kidney

Michael Freundlich

mfreundlich@med.miami.edu

1 Department of Pediatrics, Division of Pediatric Nephrology, University of Miami Miller School of Medicine, Miami, FL, USA

2 Molecular Physiology Unit, Instituto de Investigaciones Biomédicas, Universidad Nacional Autónoma de México, Mexico City, Mexico

3 Department of Nephrology, Instituto Nacional de Ciencias Médicas y Nutrición Salvador Zubirán, Mexico City, Mexico

4 Department of Nephrology, Instituto Nacional de Cardiología Ignacio Chávez, Mexico City, Mexico function [4]. These associations and the mechanisms by which FGF23 induces hypertrophy of cardiomyocytes in vivo and in vitro have been previously reviewed in this journal [5]. Recent preclinical observations have demonstrated direct effects of FGF23 on the distal convoluted tubule resulting in increased sodium $(\mathrm{Na})$ reabsorption, blood volume expansion, and HTN [6]. However, clinical studies in patients with moderate CKD do not support the notion that FGF23 exerts a clinically significant role as an important Na-retaining hormone causing HTN [7, 8]. The present article will attempt to clarify some of these discrepancies; summarize the complex relationships between the FGF23-Klotho axis, alterations of vitamin D metabolism, and the renin-angiotensin-aldosterone system (RAAS); and review therapeutic options directed at attenuating the described disturbances causing HTN.

\section{Brief overview of the FGF23-Klotho axis}

\section{FGF23 characteristics and function}

FGF23 is produced by the bone osteoblasts and osteocytes, signals through four FGF receptors (FGFR 1, 2, 3, and 4), and requires membrane-bound Klotho for binding in target tissues [9]. FGFR1 is the predominant receptor mediating phosphaturia in vivo [10]. The major cellular source of circulating FGF23 is the bone (osteocytes and osteoblasts) [9]; however, 
other cell types such as immune cells may become relevant sources of circulating FGF23 in systemic inflammatory processes [11]. In the kidney, its key target organ, FGF23 binds to the tubular Klotho. The FGFR1/Klotho complex activates various kinases, including serum glucocorticoid-regulated kinase-1 (SGK1), and suppresses the reabsorption of phosphate (Pi) through downregulation of the type II sodium-dependent phosphate $(\mathrm{NaPi})$ cotransporters $\mathrm{NaPi} 2 \mathrm{a}$ and $\mathrm{NaPi} 2 \mathrm{c}$ in the proximal tubule [12]. FGF23 also suppresses $1 \alpha$-hydroxylase, the key enzyme for production of the biologically active $1,25(\mathrm{OH})_{2} \mathrm{D}$, and downregulates the secretion and synthesis of parathyroid hormone (PTH). Thus, FGF23 not only increases urinary Pi excretion but indirectly suppresses intestinal $\mathrm{Pi}$ absorption by downregulating the production of $1,25(\mathrm{OH})_{2} \mathrm{D}$. Conversely, PTH increases FGF23 directly by acting on osteoblasts/osteocytes, and indirectly by increasing $1,25(\mathrm{OH})_{2} \mathrm{D}$ that stimulates bone FGF23 transcription in the gene promoter region [13]. FGF23 can also be regulated by PTH or calcium $(\mathrm{Ca})$ through pathways independent of $1,25(\mathrm{OH})_{2} \mathrm{D}$ and the vitamin $\mathrm{D}$ receptor (VDR), as demonstrated in VDR-ablated animals [14] and in patients with vitamin D-dependent rickets type 1 that are unable to synthesize $1,25(\mathrm{OH})_{2} \mathrm{D}[15]$. The sympathetic nervous system can also stimulate FGF23 production in bone by $\beta$-adrenergic signaling pathways and contribute to circulating FGF23 levels [16]. Finally, changes in serum or dietary Pi may also modulate FGF23 production by as yet undetermined mechanisms [9]. Thus, three hormones that control mineral metabolism, i.e., PTH, $1,25(\mathrm{OH})_{2} \mathrm{D}$, and FGF23, are interconnected to each other establishing a feedback loop between kidney, bone, the intestinal tract, and the parathyroid gland $[9,10,12,13,15]$.

Evaluating circulating levels of FGF23 requires recognizing differences in the FGF23 assays currently in use by ELISA kits. The Intact ELISA uses two antibodies that recognize the $\mathrm{N}$-terminal and $\mathrm{C}$-terminal regions and therefore only recognizes the full, intact FGF23 hormone prior to proteolytic cleavage. The two antibodies used in the C-terminal ELISA detect epitopes within the $\mathrm{C}$-terminal region and therefore this assay recognizes both the intact hormone and the $\mathrm{C}$-terminal fragment [9]. The C-terminal assay has better stability than the intact assay, and correlation between the assays is not consistent [11]. Therefore, differences in the assays should be considered when interpreting the meaning and relevance of the associations of FGF23 levels with BP or other CV disease markers [17].

\section{Klotho characteristics and function}

The klotho gene is situated on the large arm of human chromosome 13 and is expressed mostly in both distal and proximal tubules of the kidney but also in other tissues like the choroid plexus and parathyroid glands [12]. Klotho is cleaved and released from the kidney into circulation as a full-length protein or as KL1 and KL2 fragments; these circulating isoforms are collectively called "soluble" Klotho (sKL) $[9,12]$. Membrane Klotho cleavage is mediated by the A disintegrin and metalloprotease containing proteins 10 and 17 (ADAM 10 and ADAM 17, respectively) [18]. Klotho expression is stimulated by VDR activators that bind to vitamin Dresponsive elements in the Klotho gene promoter [19]. Erythropoietin, rapamycin, statins, fosinopril, and losartan are all reported to increase Klotho mRNA expression, but the underlying mechanisms remain unclear [20]. Factors that suppress Klotho gene transcription include angiotensin II (Ang II), FGF23, inflammation, oxidative stress, uremic toxins, epigenetic methylation, and hypoxia, frequently involving upregulation of the $\mathrm{Wnt} / \beta$ catenin pathway and transforming growth factor- $\beta$ (TGF- $\beta$ ) [21]. Klotho attenuates HTN and is involved in reno-protective mechanisms demonstrated in several preclinical models [22], but a specific receptor for Klotho has not been identified.

Klotho plays a key role in the FGF23-mediated effects on distal tubular $\mathrm{Na}$ transport and $\mathrm{BP}$ regulation [6]. It was believed that Klotho was only expressed in the distal tubule, but using an antibody directed against the membrane-bound Klotho isoform, Klotho protein expression was detected in both proximal and distal tubules, thus providing an explanation for the activity of circulating FGF23 on the proximal tubule downregulating the NaPi $2 \mathrm{a}$ and promoting phosphaturia in a Klotho-dependent fashion [12]. The role of Klotho as a co-receptor with FGFR1 and the importance of FGFR1 as the main FGF receptor mediating the phosphaturic effect of FGF23 on the proximal tubule are strongly supported by experimental observations demonstrating hyperphosphatemia and resistance to the phosphaturic effect of FGF23 in mice with a specific deletion of $f g f r l$ in proximal kidney tubules [10]. However, complete abolishment of phosphaturia requires abolishment of $f g f r l$ and $f g f r 4$ indicating that the FGFR4 activity plays some role, albeit less prominent, for FGF23-mediated regulation of Pi by the kidney [23]. However, Klotho may exert phosphaturic properties not only as a co-receptor for FGF23 but as an FGF23-independent hormone as evidenced by intact phosphaturia following injection of soluble Klotho in the FGF23-/- mouse and in cultured cells in the complete absence of FGF23 [24].

Thus, Klotho is a central player in the suppression of $\mathrm{NaPi}$ activity [12] and increases the cell-surface abundance of outer medullary potassium $(\mathrm{K})$ channels (ROMK) thus promoting phosphaturia and increased tubular secretion of $\mathrm{K}$, resulting in kaliuresis [25]. Additional actions of Klotho in the kidney include stimulation of the transient receptor potential channel of the vanilloid family (TRPV5) in distal tubules that are essential for $\mathrm{Ca}$ transport, regulation of $\mathrm{Na}$ reabsorption, and protection of the kidney from oxidative injury $[6,9,12]$. To exert its action, Klotho needs to be cleared from the circulation and enter the tubular lumen by transcellular trafficking 
(transcytosis) from the basolateral to the apical membrane of the tubular cell and is then secreted across the apical membrane into the urinary lumen [26]. Thus, detection of Klotho in the urine has been demonstrated by some [26], but not by others [27]. Since the kidney is the main source of circulating Klotho, it is not surprising that CKD is a state of Klotho deficiency. Reduced circulating levels and suppressed renal Klotho expression may [28] or may not [29] be associated with adverse outcomes in CKD patients. Discrepancies in the results may in part be due to technical issues concerning handling of the specimens and the high variability in results obtained with commercial ELISA assays [30]. Poor interassay and intra-assay agreement have been shown employing different currently available commercial Klotho ELISA assays, and measurement of soluble Klotho using commercial ELISA is highly unstable in human urine even when stored at $-80^{\circ} \mathrm{C}$ [31]. Therefore, variance in sample type, quality, collection and processing methods, vintage and conditions of storage, and number of freeze-thaw cycles can all drastically affect assay performance and yield widely disparate results. In a recent study, immunoprecipitation-immunoblot compared with ELISA exhibited a stronger direct correlation with estimated glomerular filtration rate (eGFR), better recovery (capture) of added exogenous Klotho, less susceptibility to variability from sample additives (protease inhibitors), and much better differentiation across different kidney disease groups, including AKI and CKD, in reference to healthy volunteers. The immunoprecipitation-immunoblot assay performance also declined after multiple freeze-thaw cycles, favoring the use of never-thawed samples when measuring soluble Klotho [30].

\section{FGF23, Klotho, and phosphate associations with hypertension}

\section{FGF23 and hypertension}

The association between elevated levels of FGF23 with BP levels have clinical implications for individuals with and without CKD. Genetic factors may determine associations of FGF23 with HTN. Polymorphisms located near genes encoding enzymes and transporters involved in vitamin D metabolism and tubular transport of $\mathrm{Pi}$ and $\mathrm{Na}$ and of the FGF23 gene are associated with the risk of developing primary $\operatorname{HTN}[32,33]$.

Although racial differences may affect both FGF23 and BP levels, whether FGF23 is associated with rising BP and racial differences in prevalent or incident HTN remains unclear. African Americans have earlier onset and higher prevalence of HTN than Whites [34], and African Americans and Hispanic patients with CKD and HTN (on dialysis or not) did have higher BP but lower FGF23 levels than comparable
White patients [35]. Similarly, in healthy young adults, higher FGF23 levels were independently associated with rising BP over time and with an increased risk of incident HTN, but without racial differences in HTN rates; these findings do not explain the disparate burden of HTN in African Americans [36]. In patients with reduced GFR, higher FGF23 levels were demonstrated in patients with HTN and moderate CKD [37]. In children and adolescents with CKD, higher systolic BP $z$-scores were associated with higher FGF23 levels [38], but the association of high FGF23 and high BP is not consistent, and other investigations found a weak association between FGF23 levels and HTN which was further attenuated after adjusting for kidney function [39]. Of interest, CKD patients randomized to intensive BP lowering compared with those in the standard regimen group sustained a significant increase in FGF23 levels after 1 year of observation, highlighting that changes in FGF23 and BP did not trend in the same direction [40]. A strong evidence against direct effects of FGF23 on BP comes from studies in a model of X-linked hypophosphatemic rickets in mice with a missense mutation in the phosphate-regulating gene with homologies to endopeptidase on the $\mathrm{X}$ chromosome. This particular model is characterized by increased production and secretion of bone FGF23 and high FGF23 levels and does not have HTN [41].

\section{FGF23 and tubular handling of sodium}

The activity of FGF23 on the distal convoluted tubule (DCT) [6] may have clinical implications and merit a concise summary of tubular Na handling.

The thiazide-sensitive sodium-chloride-cotransporter (NCC) expressed in the DCT is responsible for a large fraction of the net $\mathrm{Na}$ and chloride $(\mathrm{Cl})$ reabsorption [42]. The DCT is divided into two regions: the DCT1 or "early" DCT in which $\mathrm{Na}$ reabsorption is solely due to the NCC, and the DCT2, or "late" DCT, where Na reabsorption occurs through both the $\mathrm{NCC}$ and the epithelial sodium channel (ENaC) [42], the latter largely by the actions of aldosterone on the mineralocorticoid receptor [43]. Loss of function mutations in SLC12A3, the gene encoding the NCC, causes Gitelman's syndrome characterized by salt-wasting, K loss, and low BP [44], and increased NCC activity results in familial hyperkalemic hypertension (FHHt), also known as pseudohypoaldosteronism type II or Gordon syndrome [45]. Thiazide diuretics block the NCC and mimic Gitelman's syndrome. NCC function requires phosphorylation of various kinases, including a family of serine/ threonine kinases lacking the catalytic lysine, "with no lysine K/kinase" (WNKs), known as WNK1 to WNK4; WNK mutations result in increased salt reabsorption and HTN and cause FHHt [45]. In addition to genetic mutations, multiple factors increase the activity of the NCC by direct or indirect mechanisms, including Ang II, aldosterone, insulin, 
vasopressin, $\mathrm{Ca}$, reduced $\mathrm{Cl}$, and $\mathrm{K}$ depletion with hypokalemia $[42,45]$. The role of WNKs activation in FGF23 signaling was initially demonstrated by modifying the expression of the WNK pathway [46] and by genetically ablating the NCC gene [47]. Elevation of both FGF23 and aldosterone levels in NCC null mice (a model of mild volume depletion) suggested an aldosterone-dependent effect as the result of volume depletion, since this hormone was increased, and the increased FGF23 levels declined after treatment with the mineralocorticoid receptor blocker eplerenone [47]. Upregulation of expression and transcription of osteoblast FGF23 induced by aldosterone may be the result of increased cytosolic $\mathrm{Ca}$, mediated by SGK1 and store operated Ca entry [48].

In the most extensive study about the effects of FGF23 on the NCC activity, both FGF23-/- VDR-/-, and double Klotho-/- VDR-/- knockout mice exhibited a $\mathrm{Na}$ wasting phenotype, volume depletion, reduced BP, and increased aldosterone secretion [6]. The NCC expression was downregulated and the $\mathrm{ENaC}$ was upregulated without significant changes in serum K. Surprisingly, despite salt-wasting, low blood volume, and reduced BP, the plasma renin activity (PRA) did not change, and serum $\mathrm{K}$ remained unchanged or was lower. Additionally, recombinant FGF23 administration decreased urinary salt excretion, increased BP, and suppressed aldosterone levels without changes in PRA, while NCC phosphorylation (activity) was increased. The increased BP induced by FGF 23 administration was abrogated by chlorothiazide, a known blocker of NCC. Increased activity of NCC and $\mathrm{ENaC}$ by FGF23 is likely mediated by an increase in SGK1, with subsequent activation of the WNK1/4-STE20/ SPS-1-related proline/alanine-rich kinase (SPAK) signaling axis leading to the luminal abundance of NCC [6, 27].

The proposal that FGF23 induces HTN by promoting an increase in NCC activity through the WNK4-SPAK pathway [6] does not conform with well-established mechanisms of NCC regulation. Any primary activation of NCC is associated first with hyperkalemia and then with salt-sensitive increased BP, associated with increased aldosterone secretion and suppression of renin activity $[47,48]$. Plasma K was not reported in the mice treated with FGF23, but the finding that aldosterone secretion was reduced is difficult to reconcile with hypokalemia-induced phosphorylation of NCC as the main mechanism leading to Na retention and HTN resulting from overactivity of NCC. Of note, wild-type mice treated with recombinant FGF23 displayed a reduction in serum and urinary aldosterone, as well as downregulation of the kidney expression of $\mathrm{ENaC}$. These findings are opposite to those seen in CKD [49]. Because FGF23 induces phosphaturia and affects the Pi and Ca metabolism, and the NCC activity can be modulated by activation of the Ca sensing receptor [50], activation of the NCC could be in part mediated by changes in serum Ca. The effect of FGF23 on BP was more prominent in mice fed a low-salt diet, an observation that is counterintuitive with the proposal that hypertensive effects of FGF23 are mediated by increased activity of the NCC. The BP increase resulting from NCC overactivity is salt-sensitive and usually is decreased by low-salt diet, not increased. Finally, in two recent studies of adult [7] and pediatric [8] patients with a wide range of kidney function, FGF23 levels were positively correlated with the fractional excretion of sodium (FENa), arguing against salt retention induced by FGF23.

The formulation that the FGF23 effects on the NCC provided an explanation for the volume-dependent HTN and subsequent left ventricular hypertrophy (LVH) in CKD is based on experiments in non-uremic models [6] and may assume a decreased FENa as CKD progresses. This contradicts seminal studies in animals and patients with CKD demonstrating an increase in FENa proportional to the decline in GFR to maintain $\mathrm{Na}$ balance [51-53]. Increased natriuresis was achieved through a reduction in either proximal [53] or distal tubular $\mathrm{Na}$ reabsorption [54]. Increased FENa was associated with reduced expression of proximal tubule $\mathrm{Na}$ transporters and increases of NCC in the DCT [49], the latter interpreted as compensatory to increased delivery of $\mathrm{NaCl}$ from the proximal tubule and higher aldosterone levels. Other studies have demonstrated variable expression of proximal and distal $\mathrm{Na}$ transporters depending on the chronicity of CKD, with marked reductions of both the proximal tubule sodiumhydrogen exchanger 3 (NHE3) and the distal NCC at later stages [55]. In a model of proteinuria with moderate CKD and increased FGF23 levels, tubular NCC expression was similar to that in control animals with normal FGF23 levels [56], suggesting that factors other than the prevailing concentrations of FGF23 may determine NCC activity in the DCT. Notwithstanding differences in the experimental conditions of the mentioned studies, the collective evidence discussed earlier is not consistent with universal NCC upregulation in experimental CKD.

Data on renal tubular handling of $\mathrm{Na}$ with simultaneous FGF23 and BP measurements in patients with moderate CKD are scanty. In both studies previously mentioned [7, 8], FENa was indeed associated positively with FGF23 levels (Fig. 1a), challenging the notion that FGF23 causes clinically significant $\mathrm{Na}$ retention. In addition, FENa correlated positively with FEPi (Fig. 1b) and negatively with eGFR (Fig. 1c), consistent with the possibility that FGF23 is involved in maintaining not only Pi but also Na homeostasis as GFR progressively declines. Furthermore, children with lower GFR showed significantly higher PRA values, a finding not expected with volume expansion (Fig. 1d), FENa did not correlate with PRA, and FGF23 was not associated with BP [8]. Of note, in the alluded study of adults [7], the weak positive correlation of systolic BP with FGF23 by univariate analysis disappeared after multivariate adjustment. The relationships observed in our cohort of children, particularly the negative association of FENa with eGFR and the positive association 
Fig. 1 Associations of fractional excretion of sodium (FENa) with a FGF23 levels, b fractional excretion of phosphate (FEPi), and c cystatin $\mathrm{C}$ estimated glomerular filtration rate (eGFRcys) in children with CKD. FENa was positively associated with FGF23 and FEPi and negatively associated with eGFRcys. Plasma renin activity (PRA) (d) was significantly higher in the patients with CKD stages 2 and 3; PRA values are presented as median with interquartile ranges (brackets) from $n$ $=50$ excluding one outlier value. Values $* P<0.05$ compared with CKD stage 1 . Reproduced from [8], used with permission a

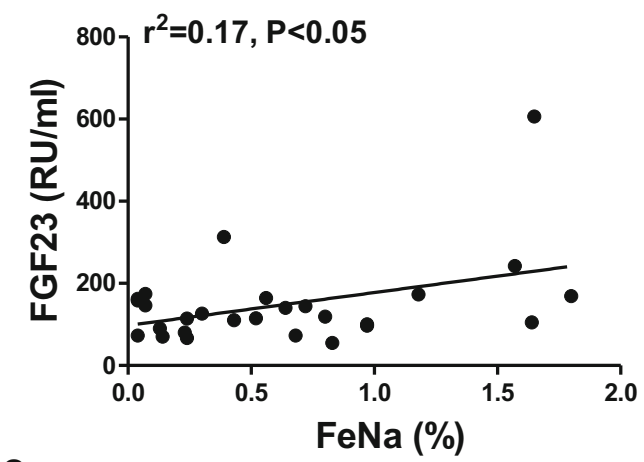

C

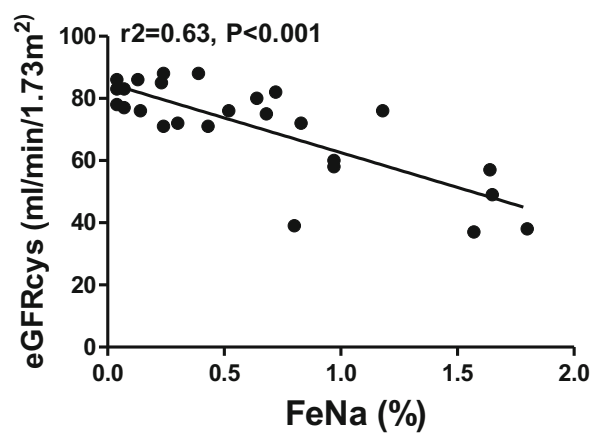

b
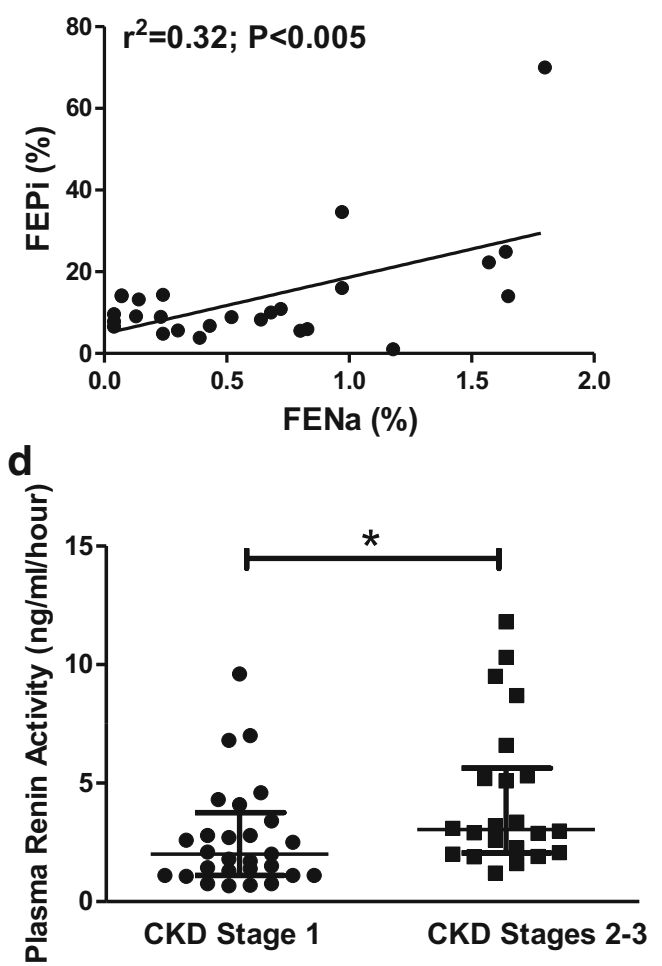

with FEPi, suggest that FENa and FEPi increase as kidney function declines, in agreement with the original observations in uremic patients [52]. In an attempt to reconcile the observations in the non-uremic animal model with the mentioned studies in CKD, it may be suggested that in earlier stages of $\mathrm{CKD}$, downregulation of proximal $\mathrm{Na}$ (and $\mathrm{Pi}$ ) reabsorption described above and discussed in a subsequent section (see below) may counteract the activation of distal FGF23 saltretentive mechanisms. The pathophysiological complexities of human CKD may affect the various biochemical measurements at different times and are further discussed in the subsequent sections.

\section{Klotho and hypertension}

Several Klotho gene polymorphisms have been recognized and linked to kidney diseases. Klotho gene deficiencies in animals [57] and polymorphisms in humans [58] are associated with salt-sensitive HTN. Genetic polymorphisms have been associated with mortality on hemodialysis [59], with higher risk of developing kidney failure (CKD stage 5) in children with CKD [60], and with HTN and higher 24-h urinary $\mathrm{Na}$ excretion in adolescents [61]. Circulating Klotho levels are reduced in children with CKD [62, 63] and in patients with primary HTN [64], and urinary Klotho levels were correlated with higher BP [65]. Downregulation of Klotho has been found in experimental HTN [66] and the silencing of the
Klotho gene results in HTN and increased aldosterone synthesis in human adrenocortical cells [67].

\section{Phosphate and hypertension}

Phosphate may be a contributor to or an independent cause of HTN. High Pi diets increase Pi, FGF23 levels, and BP, with persistent HTN after normalization of FGF23, without changes in urinary $\mathrm{Na}, \mathrm{PRA}$, or aldosterone levels [68]. These findings coincided with increases of urinary metanephrine and normetanephrine suggesting Pi- mediated sympathetic activation and raise the possibility that factors independent of FGF23 play a role in the modulation of BP [68]. Similarly, in patients with moderate CKD (mean eGFR $71 \pm 22 \mathrm{ml} / \mathrm{min} /$ $1.73 \mathrm{~m}^{2}$ ), those who simultaneously had high FGF23 levels and significantly higher serum Pi displayed the highest allcause mortality and CV disease events [69].

Of interest, Pi depletion or hypophosphatemia have the opposite effects and can decrease BP and cardiac index [70]. Overexpression of FGF23 leads to marked hypophosphatemia, cardiac hypertrophy, and hypotension, with activation of the RAAS and the sympathetic nervous system, all of which are corrected by diet-induced elevation of $\mathrm{Pi}$ [71]. However, in children with hypophosphatemia, BP can be normal [72] and conceivably the chronicity of the hypophosphatemia [71] could help explain the contrasting findings in children with lifelong 
hypophosphatemia [72] and the findings in short-term hypophosphatemia [73].

In patients with X-linked hypophosphatemia (XLH), HTN was detected in those with hyperparathyroidism that could stimulate aldosterone secretion and elevate BP [74], and in a recent study, HTN was observed only in a minority of children (2/23) with elevated FGF23 levels [75], in keeping with most prior studies that failed to document overt HTN in XLH $[72,76]$. In this study, FGF23 levels were not measured [76], and other factors mentioned earlier, like the severity and chronicity of hypophosphatemia, could explain some of these discrepancies. Conceivably, deleterious effects of FGF 23 on CV and kidney health, particularly in conditions with preserved GFR, may require a "second hit" such as RAAS dysregulation [15].

Thus, while there may be increased risks of HTN and CV changes in some patients with XLH, it remains to be shown that these abnormalities are related to elevated FGF23 levels or changes in serum Pi. The association of FGF23 with CV risks continues to be an open question, and causality is yet to be proven [17].

\section{FGF23 and Klotho interactions with the RAAS and Vitamin D}

In the classical RAAS, angiotensin-converting enzyme (ACE) removes two peptides from Ang I and generates Ang II, a potent vasoconstrictive octapeptide that directly increases BP and stimulates aldosterone, an additional cause of HTN [77]. Another axis of the RAAS depends on ACE2 that generates Ang-(1-7), a peptide with vasodilatory, anti-proliferative, and reno-protective effects via its G-protein-coupled receptor Mas [78]. Thus, ACE2/Ang-(1-7) counterbalances biological and hemodynamic actions of ACE/Ang II [79]. FGF23 is known to suppress renal ACE2 [80, 81] and thus promotes the increased prohypertensive and inflammatory effects of Ang II [79].

FGF23 levels are increased in heart failure, acute kidney injury (AKI), and CKD [5, 38, 82]. Patients with heart failure display progressively elevated PRA and FGF23 levels as the GFR decreases, in association with progressive decline of BP [83]. Elevated FGF23 expression was documented in the myocardium of young deceased patients with history of CKD [84]. Whether the elevated FGF23 levels contribute to myocardial failure by direct cardiotoxicity [4] or by driving volume expansion [85], or whether the failing heart maybe a source of circulating FGF23 [86], is not clear.

FGF23 can induce angiotensinogen (AGT) expression and, in turn, Ang II is a stimulus for FGF23 production $[5,84]$ and its expression with the co-receptor Klotho in the heart, which normally does not express FGF23 or Klotho in physiologically relevant levels [80]. Ang II can upregulate bone expression of FGF23 [48] and increase circulating FGF23 levels, with additive effects on HTN [80]. In addition, stimulation of aldosterone also stimulates bone expression of FGF23 [48]. Aldosterone levels correlated positively with left ventricular mass index and BP changes in children with treatment-naïve HTN of which 2/3 were obese [87], and in a multiethnic cohort of children with primary HTN and with a similar prevalence of obesity, baseline PRA and aldosterone levels predicted the changes in left ventricular mass index and BP $z$-scores over time while under treatment mostly with RAAS inhibitors [88]. It is noteworthy that the observed negative correlations of the baseline PRA and aldosterone measurements with the outcome changes after treatment were more robust in White patients than in Hispanic and Black patients [88], suggesting that other factors may contribute to the HTN and treatment response in non-White patients. Leptin, produced by adipocytes, can increase bone FGF23 expression [89] and also upregulate aldosterone secretion by stimulating leptin receptors in the adrenal gland cortical cells [90]. Both FGF23 and leptin levels are elevated in patients with obesity [91], and obese children frequently develop HTN, as illustrated in a study that showed $35 \%$ of 260,000 overweight and obese children had HTN [92]. FGF23 levels are higher in normotensive obese children, highlighting that FGF23 elevations are not necessarily accompanied by increases in BP and raising the possibility that FGF23 may contribute to cardiac hypertrophy in children with obesity before they develop HTN [93].

Since FGF23 inhibits 1- $\alpha$ hydroxylase activity [13], the resulting reduced $1,25(\mathrm{OH})_{2} \mathrm{D}$ levels favor renin upregulation with activation of the ACE/Ang II arm of the RAAS [94] and reduction of ACE2/Ang-(1-7) [80, 81], thus contributing to HTN. In contrast, VDR activation by paricalcitol suppresses the expression of RAAS genes in the kidney and the heart and improves kidney function, proteinuria, and cardiac hypertrophy in CKD. These effects are associated with minimal or no effects on BP $[95,96]$; nevertheless, BP can be inversely correlated with levels of $1,25(\mathrm{OH})_{2} \mathrm{D}$ [97]. Paricalcitol also downregulates AGT [96], and increases renal ACE2 and Ang-(1-7) expression [98] and, therefore, it appears that several mechanisms are operative in the modulation of the RAAS by FGF23 and vitamin D.

Reduced urinary Klotho levels were correlated with lower urinary Ang-(1-7) levels [65] and Klotho is downregulated by Ang II that can be attenuated by AT1R blockade [99]. Conversely, Klotho downregulates RAAS activity as the result of suppressing the stimulatory effects of the $\mathrm{Wnt} / \beta$ catenin pathway on the RAAS. This effect results in amelioration of HTN induced by Klotho in experimental CKD [100].

These complex interactions of FGF23, Klotho, vitamin D, and the RAAS form a feedback loop in CKD and HTN. Reduction in Klotho restrains the formation of the FGFR1Klotho complex; FGF23 resistance drives the increment in FGF23 levels which contribute to accentuate deficiency of vitamin D and ACE2. Reduction in vitamin D and ACE2 results in relative Ang II overactivity that, in turn, accentuates 
Klotho deficiency [101]. These interactions as well as their links with FGF23-mediated renal Na regulation are outlined in Fig. 2.

\section{Therapeutic interventions}

\section{Nonpharmacologic interventions}

\section{Sodium restriction and FGF23 changes}

Sodium restriction remains a cornerstone in the management of HTN mostly by attenuating volume expansion [102].
Sodium-induced changes in FGF23 levels may be linked to plasma volume changes, and higher FGF23 levels were associated with a reduced antiproteinuric response to dietary $\mathrm{Na}$ restriction and RAAS blockade [103]. FGF23 levels have been associated with markers of volume status in kidney transplant recipients [104], and in patients on hemodialysis [105]. However, in non-dialysis patients, neither acute volume expansion nor severe Na restriction (resulting in lower BPs) induced significant changes in circulating FGF23 concentrations [85]. These latter observations did not support a direct feedback loop between volume status and FGF23 in patients with HTN and incipient CKD. However, in normal individuals, the change from a low- to a high-Na diet associated with

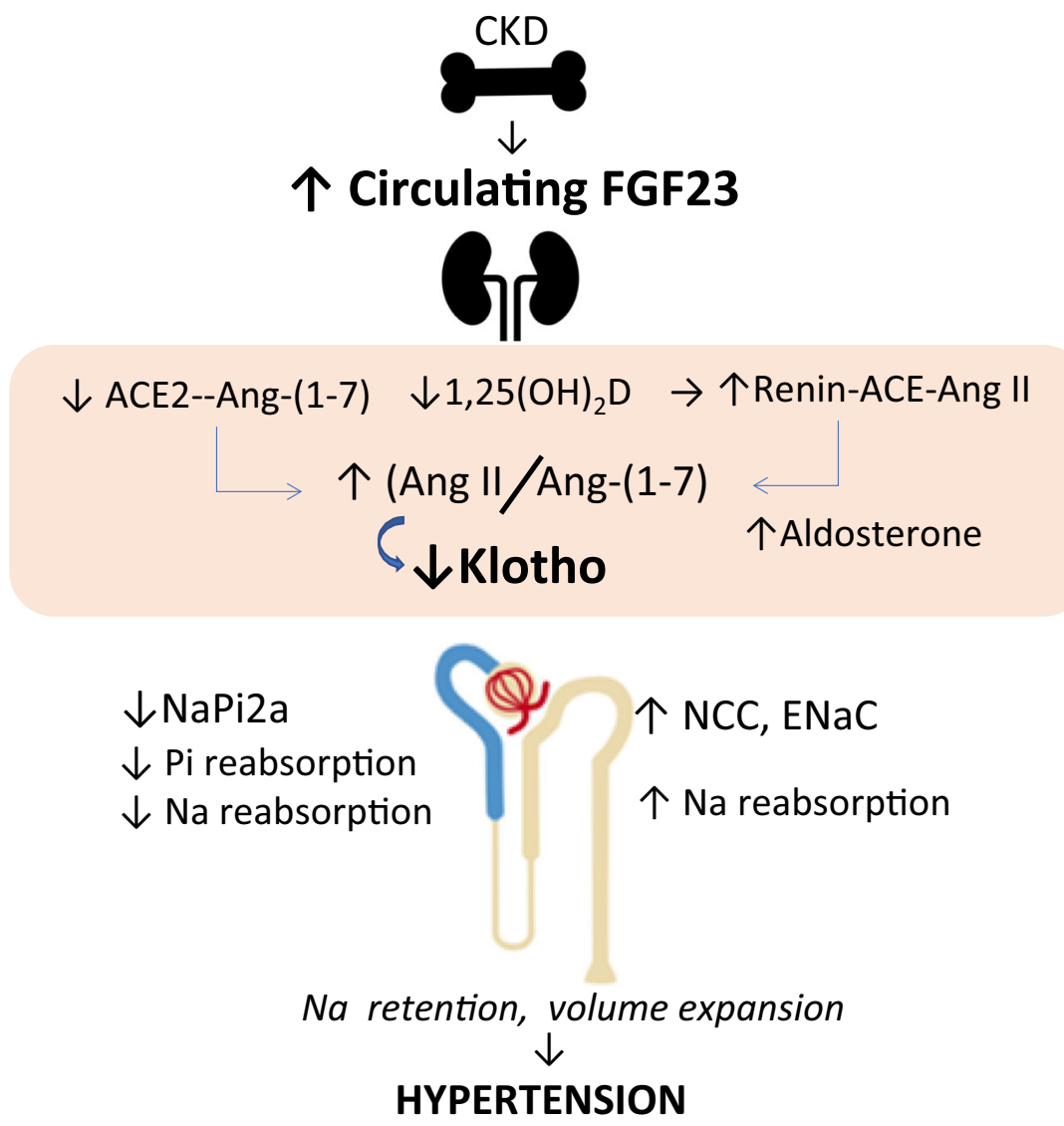

Fig. 2 Excess FGF23 and Klotho insufficiency links to vitamin D, the RAAS, sodium homeostasis, and hypertension in CKD. Augmented FGF23 production by the bone results in elevated circulating FGF23 levels. FGF23 effects in the kidney are mediated by activation of the FGFR1/Klotho complex and result in reduced 1,25(OH)2D synthesis, upregulated renin with increased ACE/Ang II, and reduced ACE2/Ang(1-7) formation, leading to an elevated Ang II/Ang-(1-7) ratio, which contribute to sodium retention, kidney damage, and hypertension. Membrane-bound Klotho is normally induced by $1,25(\mathrm{OH}) 2 \mathrm{D}$, therefore reduced 1,25(OH)2D, and elevated Ang II (via the Ang II type 1 receptor, not shown), both suppress Klotho production. The latter contributes to FGF23 resistance further augmenting FGF23 levels. FGF23 also acts separately on both the renal proximal and the distal tubules mostly in a Klotho-dependent fashion but by distinctly different signaling systems (not shown). In the proximal tubule (blue), FGF23 inhibits the re- uptake of phosphate by regulating the sodium phosphate transporter $\mathrm{NaPi} 2 \mathrm{a}$ (and $\mathrm{NaPi} 2 \mathrm{c}$, not shown). Since $\mathrm{NaPi} 2 \mathrm{a}$ transports three sodium ions together with phosphate, FGF23-mediated inhibition of this transporter causes natriuresis. In the distal tubule (light brown), FGF23 activates the NCC to increase reabsorption of sodium and ultimately promotes volume retention thus contributing to hypertension. While upregulation of the NCC favors hypertension, concurrent inhibition of the $\mathrm{NaPi}$ 2a may counterbalance these sodium-retentive effects on vascular homeostasis and attenuate hypertension. The reduced Klotho expression in CKD restrains the formation of the FGFR1-Klotho complex; the ensuing FGF23 resistance, and the increased circulating Ang II and aldosterone, contribute to the increment in FGF23 secretion. The higher FGF23 levels contribute to accentuate deficiency of vitamin D and ACE2, which, in turn, drive Ang II overactivity that further accentuates Klotho deficiency 
the expected increase in BP and resulted in a significant decline of FGF23 levels [106], thus supporting the notion that changes in $\mathrm{Na}$ intake induce opposing regulatory changes in FGF23.

\section{Dietary phosphate modulation and FGF23 changes}

Dietary interventions directed to reduce Pi load, aiming to modify FGF23 levels in patients with CKD, have demonstrated inconsistent results, with either reduced [107] or unchanged FGF23 levels [108]. Randomized, controlled trials are needed to define potential CV benefits of lowering FGF23 through reduction of gastrointestinal absorption of Pi. As discussed above, BP changes following elevations of $\mathrm{Pi}$ are the result of sympathetic activation and did not associate with fluctuations in FGF23 levels [68].

\section{Pharmacologic interventions}

\section{Thiazide diuretics}

Because thiazides are diuretics that act directly on the NCC at the DCT, they are considered appropriate agents to offset the $\mathrm{Na}$ retention in CKD [109]. In patients with incipient CKD treated with hydrochlorothiazide, the reduction in systolic BP was unrelated to changes in circulating FGF23 levels or changes in natriuresis [85]. Further details on the use of thiazide diuretics in children have been previously discussed in this Journal [110] and are beyond the scope of the present review.

\section{NaPi 2a modulation}

Oral administration of a NaPi 2 a inhibitor (NI) to $5 / 6$ nephrectomized rats resulted in phosphaturia, decreased serum Pi, and a rapid decline of PTH and FGF23. Levels of PTH, FGF23, and Pi were noted to rebound with significantly higher values after $24 \mathrm{~h}$, when the NI effect had presumably ceased. In addition to phosphaturia, natriuresis also had a dose-dependent increase with NI administration. Similar effects, but with reduced magnitude, were observed in the uremic group (FGF23 levels were not measured) [111]. Of interest, the reduction in the proximal tubule expression of $\mathrm{NaPi} 2 \mathrm{a}$ was not associated with changes in NHE3, the major proximal tubule $\mathrm{Na}$ transporter. $\mathrm{NaPi} 2 \mathrm{a}$ is electrogenic, transporting three $\mathrm{Na}$ ions into the cell for one $\mathrm{Pi}$ ion, and the described findings suggest that the marked natriuresis resulted largely from inhibition of the NaPi 2a [111]. Notwithstanding differences in the experimental models, the lack of data on NCC, $\mathrm{ENaC}$ expression, and BP measurements [111], and the persistent natriuresis in 5/6 nephrectomized animals while FG23 levels are expected to be elevated, are contrary to the stimulation of $\mathrm{Na}$ reabsorption attributed to FGF23 by other investigators, as discussed earlier. Along the same lines, the lack of changes in the NHE3 expression following NI administration differs from the reduced NHE3 expression of uremic animals shown by others $[49,55]$.

Studies in uremic animals that relate BP, FGF23 levels, and kidney expression levels of FGFRs and Na-regulating cotransporters in the proximal and DCT have not, to our knowledge, been reported and may clarify some of the discrepancies listed earlier. It is conceivable that elevated FGF23 levels in moderate CKD, by their effects on the $\mathrm{NaPi}$ cotransporters, may contribute to the increases in the FENa, and function as an intrarenal homeostatic loop opposing the described Na reabsorption of the DCT (see Fig. 2). The direct correlation of FENa and FEPi (Fig. 1) in our patients with moderate CKD stages 2 and 3 and with elevated FGF23 levels [8] supports this possibility.

\section{RAAS modulation}

As mentioned earlier, FGF23 contributes to RAAS activation and Ang II increases FGF23 bone expression and circulating levels [48, 84]; therefore, both FGF23 and Ang II pathways contribute to HTN. Of note, FGF23 blunts the nephroprotective effects of ARBs, inhibits the ARB-mediated gene expression of Klotho in the kidney, and attenuates the expression of anti-inflammatory genes [112]. Clinically, BP control was similar in patients receiving either ramipril or amlodipine, but proteinuria declined more markedly and FGF23 levels fell significantly only in those receiving ramipril [113]. Proteinuria interferes with FGF23 signaling via decreased Klotho expression, and children with normal GFR and nephrotic syndrome during relapses of proteinuria display high plasma FGF23 levels that drop and normalize during remission [56]. Although BP changes were not reported in these children [56], in adults with CKD stages 1 to 4 due to IgA nephropathy, FGF23 levels increased in parallel with albuminuria and significantly predicted CKD progression independently of BP changes [114]. Thus, the reduction of FGF23 levels following RAAS inhibitors may contribute to the established benefits of suppression of the RAAS in patients with CKD, proteinuria, and HTN.

As previously discussed, FGF23 reduces ACE2 and Ang-(1-7) levels $[80,81]$ and prevents ARB-mediated increased kidney ACE2 mRNA expression [112], which drives Ang II/AT1R predominance. Therefore, antagonizing the FGF23-mediated reduction of ACE2/Ang-(1-7) may provide a strategy to reduce Ang II activity. Reduction of renal ACE2 can be minimized with the VDR activator paricalcitol that blocks tubular ACE2 shedding by metallosecretases [98]. Excess FGF23, elevated Ang II, and reduction of ACE2/Ang-(1-7) are therefore desirable targets of ACEI and ARB therapy. Inflammation resulting from infection stimulates bone FGF23 production leading to elevated FGF23 
circulating levels [11]. Therefore, one could speculate that FGF23 by reducing ACE2, the receptor that facilitates the cellular entry of viral particles such as SARS-CoV-2 [115], may further promote Ang II-mediated effects on target tissues and affect BP regulation. This would also support the currently recommended guidelines of maintaining the treatment with ARBs and ACE inhibitors, when medically indicated, in patients with SARS-CoV-2 infection [116-118].

The exogenous administration of human recombinant ACE2 (rACE2) increases serum ACE2 activity with degradation of circulating Ang II and attenuation of Ang II-mediated HTN [119]. In patients affected by pulmonary HTN, a common complication of patients with advanced CKD 5D, rACE2 infusion resulted in significant reductions of systemic BP and a decreased plasma Ang II/Ang-(1-7) ratio, suggesting effective ACE2 augmentation [120]. Thus, rACE2 is a novel therapeutic option with potential beneficial effects in conditions involving excess FGF23.

Bone production of FGF23 can also be upregulated by aldosterone [48], and both aldosterone and FGF23 levels are elevated in obese children with HTN $[87,91]$. Since the aldosterone-mediated upregulation of FGF23 can be reversed by mineralocorticoid receptor blockers like spironolactone and eplerenone [48], therapeutic agents suppressing aldosterone activation (i.e., mineralocorticoid receptor antagonists) should be considered an option in children with HTN and obesity [121].

\section{Vitamin D and calcimimetics}

\section{Vitamin D}

Vitamin D insufficiency is very prevalent in children with CKD [122] and is associated with HTN [123]. Nutritional vitamin D oral supplementation reduces circulating RAAS levels and improves HTN [124].

Of note, VDR agonists stimulate bone production of FGF23 and can further elevate circulating FGF23 levels in CKD [125]. However, a significant direct relationship of BP with FGF23 levels was not observed in young patients with CKD $[8,96]$. Furthermore, VDR agonists reduce aldosterone secretion and circulating levels [126], preserve ACE2 [98], and prevent renal Klotho reduction [127] and thus may indirectly attenuate hypertension.

\section{Calcimimetics}

Calcimimetics (cinacalcet and etelcalcetide) enhance the calcium-sensing-receptor sensitivity for extracellular $\mathrm{Ca}$, and induce reduction in serum $\mathrm{PTH}, \mathrm{Ca}$, and P levels $[128,129]$. Calcimimetics consistently lower the circulating FGF23 levels, largely mediated by reductions of $\mathrm{Ca}, \mathrm{Pi}$, and $\mathrm{Ca} \times \mathrm{P}$ product, independently of changes in PTH [130]. However, data on the relationships of FGF23 with BP and Na homeostasis during treatment with calcimimetics in young patients with CKD are virtually non-existent. In a single study of children on dialysis treated with cinacalcet, systolic and diastolic BP levels remained unchanged after 3 months of therapy, but FGF23 levels were not measured [131]. In the EVOLVE trial of adult patients with CKD 5D, cinacalcet resulted in significantly lower systolic and diastolic BP compared with placebo and may have contributed to a better cardiovascular outcome [132]. However, the precise mechanisms by which calcimimetics exert changes on BP regulation in patients with HTN are not clear.

\section{FGF23 blocking agents}

As discussed earlier, FGF23 signals through FGFRs, mainly through FGFR1 and FGFR4 in the kidney and heart, respectively. Although pan-FGFR blocking agents or FGFR4specific blocking agents can attenuate kidney dysfunction and cardiac hypertrophy in experimental uremia, their effects on HTN are modest at best $[4,96]$. Furthermore, global effects of pan-FGFR blockers or FGFR1 blockers may have undesirable consequences such as blunting the FGFR1-mediated phosphaturic effect of FGF23 with subsequent hyperphosphatemia, vascular calcification, and increase in mortality [133].

Similarly, treatment with an anti-FGF23 monoclonal antibody such as burosumab [134] may cause enhanced proximal tubular Pi reabsorption and increased serum Pi and $1,25(\mathrm{OH})_{2} \mathrm{D}$ in earlier stages of CKD. This therapy may be less risky in patients with CKD 5D when hyperphosphatemia management is not dependent on increased phosphaturia, and its use to attenuate cardiac hypertrophy may be considered a justifiable endpoint for future clinical trials. Burosumab is the first treatment that specifically addresses the underlying pathophysiology of XLH rickets through blockade of excess circulating levels of FGF23, thereby increasing renal Pi reabsorption and normalizing hypophosphatemia [134]. As mentioned in a section above, HTN is present in a minority of pediatric patients with XLH $[74,75]$. Future studies with burosumab will be helpful to define whether long-term blockade of systemic FGF23 in patients with XLH rickets may result in cardiac or BP changes. A list of currently in use and preclinical therapeutic strategies aimed at interfering directly or indirectly with the effects of FGF23 homeostatic disturbances in CKD is listed in Table 1.

\section{Klotho reactivation and exogenous administration}

Prevention of Klotho decline, reactivation of endogenous Klotho production, and supplementation of exogenous Klotho are therapeutic strategies worth considering in CKD. 
Table 1 FGF23-targeted therapeutic strategies to improve hypertension in CKD

\begin{tabular}{ll}
\hline Intervention & FGF23-Klotho-linked effects \\
\hline $\begin{array}{l}\text { Thiazide diuretics and sodium restriction } \\
\begin{array}{l}\text { Dietary phosphate restriction and phosphate } \\
\text { binders }\end{array}\end{array}$ & $\downarrow$ NCC, $\downarrow$ sodium reabsorption $\uparrow$ natriuresis, $\downarrow$ volume expansion, vasodilation $\rightarrow \downarrow$ BP \\
$\begin{array}{l}\text { Oral blocking agent of tubular phosphate } \\
\text { reabsorption (preclinical phase) }\end{array}$ & $\downarrow$ NaPi 2a activity, $\uparrow$ phosphaturia, $\downarrow$ serum phosphate $\rightarrow \downarrow$ FGF23 \\
RAAS inhibition (ACEI, ARB) & $\downarrow$ Sodium reabsorption, $\uparrow$ ACE2/Ang-(1-7) (relative to ACE/Ang II) interferes with FGF23 effects, \\
& $\downarrow$ bone FGF23 secretion, $\uparrow$ Klotho, $\uparrow$ cardio-kidney protection $\rightarrow \downarrow$ BP \\
Mineralocorticoid receptor blockers in obesity & $\downarrow$ Leptin, $\downarrow$ aldosterone, $\downarrow$ FGF23 $\rightarrow \downarrow$ BP \\
$\begin{array}{l}\text { Dietary vitamin D and VDR activators } \\
\text { Calcimimetics }\end{array}$ & $\downarrow$ Renin and ACE/Ang II, $\uparrow$ ACE2/Ang-(1-7), $\uparrow$ Klotho, $\uparrow$ cardio-kidney-protection $\rightarrow \downarrow$ BP (indirectly) \\
Humanized anti-FGF23 monoclonal antibody & $\downarrow$ PTH, $\downarrow$ FGF23 (long-term salutary effects?) \\
$\quad$ burosumab) & Blocks FGF23 activation on receptor. Improves hypophosphatemia, bone, and growth derangements \\
in XLH. & Unknown effects on BP and cardiac hypertrophy in CKD \\
Recombinant ACE2 (preclinical and early & $\uparrow$ Serum ACE2, $\uparrow$ degradation of Ang II \\
clinical) & $\uparrow$ Ang-(1-7) $\rightarrow \downarrow$ systemic BP, $\downarrow$ pulmonary BP. Attenuates kidney damage \\
Exogenous Klotho administration & $\downarrow$ Ang II levels, $\uparrow$ Klotho kidney expression, $\uparrow$ kidney perfusion, $\downarrow$ BP
\end{tabular}

$F G F 23$, fibroblast growth factor 23; $B P$, blood pressure; $N C C$, sodium chloride cotransporter; $N a P i 2 a$, sodium phosphate cotransporter; $R A A S$, reninangiotensin-aldosterone system; $A C E$, angiotensin-converting enzyme; $A C E 2$, angiotensin-converting enzyme 2; $A C E I, A C E$ inhibitor; $A R B$, angiotensin receptor blocker; Ang II, angiotensin II; Ang-(1-7), angiotensin-(1-7); XLH, X-linked hypophosphatemia. For corresponding references, see text

Reactivation of endogenous Klotho can be achieved by various strategies. In the ESCAPE trial of children with $\mathrm{CKD}$, patients treated with ramipril compared with baseline displayed significantly higher Klotho and lower BP levels [135], and VDR activators upregulate Klotho in the kidneys [127] that attenuates HTN [100]. Exogenous Klotho supplementation suppresses proximal tubule epithelium $\mathrm{NaPi} 2 \mathrm{a}$ levels in the absence of membrane-bound Klotho and reduces hyperphosphatemia [136], and may provide the potential for enhancing Klotho activity or its downstream pathways in disorders characterized by reduced membrane-bound and circulating Klotho levels, with increased $\mathrm{Pi}$ and $\mathrm{Na}$ reabsorption, hyperphosphatemia, and HTN, such as CKD [62, 63]. Clinically, patients with CKD and elevated FGF23 levels may show a wide distribution of FEPi at any given FGF23 concentration, suggesting that kidney tubules may not always respond as expected to a high FGF23 stimulus [69]. This relative kidney tubule resistance to FGF23 resulting in higher FGF23 levels in an attempt to further increase Pi excretion [69] may be in part due to reduced kidney expression of the co-receptor Klotho [22, 26, 28], and additional studies evaluating Klotho exogenous administration may be considered. Similar studies are needed to evaluate whether FGF23mediated Klotho-dependent effects on tubular Na transporters and FENa can be observed following exogenous Klotho administration in CKD. Klotho is known for its multiple pleiotropic actions including cytoprotection through its ability to confer anti-oxidation, protection of vasculature, and antisenescence among others [22]. Maternal vascular malperfusion, frequently associated with small for gestational age preterm infants, results in placental aging and may affect Klotho production by the placenta; cord blood Klotho levels were measured in a case-control study and, compared to normal controls, were found to be significantly lower in infants born prematurely and with placental vascular findings consistent with accelerated aging that contributed to intrauterine growth retardation [137]. Prematurity and other perinatal exposures are associated with increased risks of cardiometabolic risk factors, $\mathrm{CKD}, \mathrm{HTN}$, and $\mathrm{CV}$ disease that are likely due to multiple intrauterine and extrauterine factors that may alter kidney, cardiac, and vascular structure and function [138, 139]. These alterations affecting perinatal programming may alter the RAAS, with lower Ang-(1-7) and a higher Ang II/ Ang-(1-7) ratio that may persist and contribute to higher BPs later in life, as documented in adolescents with a history of premature birth [140]. Of interest, these adolescents upon subsequent reevaluation as young adults displayed reduced urinary Klotho levels that were associated negatively with the urinary Ang II/Ang-(1-7) ratio and a higher BP [65].

We recently studied the effects of Klotho administration in rodents with hyperoxia-induced pulmonary and kidney damage. The rodents displayed reduced kidney Klotho expression, glomerulomegaly, and tubular injury, and exogenous Klotho administration improved kidney perfusion, increased intrarenal antioxidant capacity, and reduced kidney injury [141]. There was also improved lung vascular development, attenuated vascular remodeling, and reduced pulmonary hypertension and cardiac biventricular hypertrophy [142]. These findings may be clinically relevant because blood Klotho levels were reduced in preterm infants [142] who 
subsequently developed bronchopulmonary dysplasia and pulmonary hypertension.

\section{Conclusions}

Although FGF23 is mainly involved in regulating phosphate homeostasis, advances in experimental and clinical research over recent years have uncovered links between FGF23 with hemodynamic and cardiovascular changes potentially affecting BP. These links involve direct and indirect mechanistic connections between the FGF23-Klotho axis, vitamin D, and the RAAS. Excess FGF23, insufficient Klotho availability, and reduced $1,25(\mathrm{OH})_{2} \mathrm{D}$ synthesis engage in a cross-talk with the RAAS and modulate kidney Na reabsorption, blood volume balance, hormonal disturbances, oxidative stress, and mineral metabolism homeostasis. These interactions contribute cooperatively to elevate $\mathrm{BP}$, promote progressive kidney and vascular damage, facilitate vascular calcification, alter myocardial structure and function, and thus play a pivotal role in the high rates of cardiovascular morbidity and mortality in patients with CKD. We have discussed discrepancies in experimental and clinical studies concerning the ability of FGF23 to augment sodium tubular reabsorption and suggested alternative explanations for those differences. Some therapeutic advances outlined in this review may open new research avenues aimed at arresting kidney, pulmonary, and $\mathrm{CV}$ pathological conditions in CKD and in preterm infants.

Funding GG is partly supported by grants A1-S-8290 (Conacyt, Mexico) and DK051496 (NIH, USA). BRI is the recipient of the "Catedra Salvador Zubirán" from the School of Medicine, Universidad Nacional Autónoma de México and the Instituto Nacional de Ciencias Médicas y Nutrición Salvador Zubirán.

\section{Compliance with ethical standards}

Conflict of interest The authors declare that they have no conflict of interest.

\section{References}

1. Weaver DJ, Mitsnefes M (2018) Cardiovascular disease in children and adolescents with chronic kidney disease. Semin Nephrol 38:559-569

2. Song P, Zhang Y, Yu J, Zha M, Zhu Y, Rahimi K, Rudan I (2019) Global prevalence of hypertension in children: a systematic review and meta-analysis. JAMA Pediatr 173:1154-1163

3. Schaefer F, Doyon A, Azukaitis K, Bayazit A, Canpolat N, Duzova A, Niemirska A, Sözeri B, Thurn D, Anarat A, Ranchin B, Litwin M, Caliskan S, Candan C, Baskin E, Yilmaz E, Mir S, Kirchner M, Sander A, Haffner D, Melk A, Wühl E, Shroff R, Querfeld U, 4C Study Consortium (2017) Cardiovascular phenotypes in children with CKD: the 4C study. Clin J Am Soc Nephrol 12:19-28
4. Faul C, Amaral AP, Oskouei B, Hu MC, Sloan A, Isakova T, Gutiérrez OM, Aguillon-Prada R, Lincoln J, Hare JM, Mundel P, Morales A, Scialla J, Fischer M, Soliman EZ, Chen J, Go AS, Rosas SE, Nessel L, Townsend RR, Feldman HI, St John Sutton M, Ojo A, Gadegbeku C, Di Marco GS, Reuter S, Kentrup D, Tiemann K, Brand M, Hill JA, Moe OW, Kuro-O M, Kusek JW, Keane MG, Wolf M (2011) FGF23 induces left ventricular hypertrophy. J Clin Invest 121:4393-4408

5. Haffner D, Leifheit-Nestler M (2017) Extrarenal effects of FGF23. Pediatr Nephrol 32:753-765

6. Andrukhova O, Slavic S, Smorodchenko A, Zeitz U, Shalhoub V, Lanske B, Pohl EE, Erben RG (2014) FGF23 regulates renal sodium handling and blood pressure. EMBO Mol Med 6:744-759

7. Xu H, Hashem A, Witasp A, Mencke R, Goldsmith D, Barany P, Bruchfeld A, Wernerson A, Carrero JJ, Olauson H (2019) Fibroblast growth factor 23 is associated with fractional excretion of sodium in patients with chronic kidney disease. Nephrol Dial Transplant 34:2051-2057

8. Freundlich M, Cuervo C, Abitbol CL (2019) Fibroblast growth factor 23 and tubular sodium handling in young patients with incipient chronic kidney disease. Clin Kidney J 13:389-396

9. Olauson H, Vervloet MG, Cozzolino M, Massy ZA, Ureña Torres P, Larsson TE (2014) New insights into the FGF23-klotho axis. Semin Nephrol 34:586-597

10. Han X, Yang J, Li L, Huang J, King G, Quarles LD (2016) Conditional deletion of fgfr 1 in the proximal and distal tubule identifies distinct roles in phosphate and calcium transport. PLoS One 11:e0147845

11. David V, Martin A, Isakova T, Spaulding C, Qi L, Ramirez V, Zumbrennen-Bullough KB, Sun CC, Lin HY, Babitt JL, Wolf M (2016) Inflammation and functional iron deficiency regulate fibroblast growth factor 23 production. Kidney Int 89:135-146

12. Erben RG, Andrukhova O (2017) FGF23-klotho signaling axis in the kidney. Bone 100:62-68

13. Shimada T, Hasegawa H, Yamazaki Y, Muto T, Hino R, Takeuchi Y, Fujita T, Nakahara K, Fukumoto S, Yamashita T (2004) FGF23 is a potent regulator of vitamin D metabolism and phosphate homeostasis. J Bone Miner Res 19:429-435

14. Shimada T, Yamazaki Y, Takahashi M, Hasegawa H, Urakawa I, Oshima T, Ono K, Kakitani M, Tomizuka K, Fujita T, Fukumoto S, Yamashita T (2005) Vitamin D receptor-independent FGF23 actions in regulating phosphate and vitamin D metabolism. Am J Physiol Ren Physiol 289:F1088-F1095

15. Cuervo C, Abitbol CL, Zilleruelo GE, Freundlich M (2016) Fibroblast growth factor-23 and renin-angiotensin system levels in vitamin-D-dependent rickets type I. Pediatr Nephrol 31:11891193

16. Kawai M, Kinoshita S, Shimba S, Ozono K, Michigami T (2014) Sympathetic activation induces skeletal FGF23 expression in a circadian rhythm-dependent manner. J Biol Chem 289:14571466

17. Marthi A, Donovan K, Haynes R, Wheeler DC, Baigent C, Rooney CM, Landray MJ, Moe SM, Yang J, Holland L, di Giuseppe R, Bouma-de Krijger A, Mihaylova B, Herrington WG (2018) Fibroblast growth factor-23 and risks of cardiovascular and noncardiovascular diseases: a meta-analysis. J Am Soc Nephrol 29:2015-2027

18. Olauson H, Mencke R, Hillebrands JL, Larsson TE (2017) Tissue expression and source of circulating $\alpha$ klotho. Bone 100:19-35

19. Forster RE, Jurutka PW, Hsieh JC, Haussler CA, Lowmiller CL, Kaneko I, Haussler MR, Kerr Whitfield G (2011) Vitamin D receptor controls expression of the anti-aging klotho gene in mouse and human renal cells. Biochem Biophys Res Commun 414:557562

20. Xu Y, Sun Z (2015) Molecular basis of Klotho: from gene to function in aging. Endocr Rev 36:174-193 
21. Muñoz-Castañeda JR, Rodelo-Haad C, Pendon-Ruiz de Mier MV, Martin-Malo A, Santamaria R, Rodriguez M (2020) Klotho/FGF23 and Wnt signaling as important players in the comorbidities associated with chronic kidney disease. Toxins (Basel) 12:185

22. Hu MC, Kuro-o M, Moe OW (2012) The emerging role of Klotho in clinical nephrology. Nephrol Dial Transplant 27:2650-2657

23. Gattineni J, Alphonse P, Zhang Q, Mathews N, Bates CM, Baum M (2014) Regulation of renal phosphate transport by FGF23 is mediated by FGFR1 and FGFR4. Am J Physiol Ren Physiol 306: F351-F358

24. Hu MC, Shi M, Zhang J, Pastor J, Nakatani T, Lanske B, Razzaque MS, Rosenblatt KP, Baum MG, Kuro-o M, Moe OW (2010) Klotho: a novel phosphaturic substance acting as an autocrine enzyme in the renal proximal tubule. FASEB J 24:34383450

25. Cha SK, Hu MC, Kurosu H, Kuro-o M, Moe O, Huang CL (2009) Regulation of renal outer medullary potassium channel and renal $\mathrm{K}(+)$ excretion by klotho. Mol Pharmacol 76:38-46

26. Hu MC, Shi M, Zhang J, Addo T, Cho HJ, Barker SL, Ravikumar P, Gillings N, Bian A, Sidhu SS, Kuro-o M, Moe OW (2016) Renal production, uptake, and handling of circulating $\alpha$ klotho. J Am Soc Nephrol 27:79-90

27. Erben RG (2016) Update on FGF23 and klotho signaling. Mol Cell Endocrinol 432:56-65

28. Barker SL, Pastor J, Carranza D, Quiñones H, Griffith C, Goetz R, Mohammadi M, Ye J, Zhang J, Hu MC, Kuro-o M, Moe OW, Sidhu SS (2015) The demonstration of alpha-klotho deficiency in human chronic kidney disease with a novel synthetic antibody. Nephrol Dial Transplant 30:223-233

29. Seiler S, Wen M, Roth HJ, Fehrenz M, Flügge F, Herath E, Weihrauch A, Fliser D, Heine GH (2013) Plasma klotho is not related to kidney function and does not predict adverse outcome in patients with chronic kidney disease. Kidney Int 83:121-128

30. Neyra JA, Moe OW, Pastor J, Gianella F, Sidhu SS, Sarnak MJ, Ix JH, Drew DA (2019) Performance of soluble Klotho assays in clinical samples of kidney disease. Clin Kidney J 13:235-244

31. Neyra JA, Hu MC, Moe OW (2020) Klotho in clinical nephrology: diagnostic and therapeutic implications. Clin J Am Soc Nephrol. https://doi.org/10.2215/CJN.02840320

32. Robinson-Cohen C, Bartz TM, Lai D, Ikizler TA, Peacock M, Imel EA, Michos ED, Foroud TM, Akesson K, Taylor KD, Malmgren L, Matsushita K, Nethander M, Eriksson J, Ohlsson C, Mellström D, Wolf M, Ljunggren O, McGuigan F, Rotter JI, Karlsson M, Econs MJ, Ix JH, Lutsey PL, Psaty BM, de Boer IH, Kestenbaum BR (2018) Genetic variants associated with circulating fibroblast growth factor 23. J Am Soc Nephrol 29:2583-2592

33. Cai P, Peng Y, Li L, Chu W, Wang X (2018) Fibroblast growth factor 23 (FGF23) gene polymorphisms are associated with essential hypertension risk and blood pressure levels in Chinese Han population. Clin Exp Hypertens 40:680-685

34. Benjamin EJ, Blaha MJ, Chiuve SE, Cushman M, Das SR, Deo R, de Ferranti SD, Floyd J, Fornage M, Gillespie C, Isasi CR, Jiménez MC, Jordan LC, Judd SE, Lackland D, Lichtman JH, Lisabeth L, Liu S, Longenecker CT, Mackey RH, Matsushita K, Mozaffarian D, Mussolino ME, Nasir K, Neumar RW, Palaniappan L, Pandey DK, Thiagarajan RR, Reeves MJ, Ritchey M, Rodriguez CJ, Roth GA, Rosamond WD, Sasson C, Towfighi A, Tsao CW, Turner MB, Virani SS, Voeks JH, Willey JZ, Wilkins JT, Wu JH, Alger HM, Wong SS, Muntner P, American Heart Association Statistics Committee and Stroke Statistics Subcommittee (2017) Heart disease and stroke statistics-2017 update: a report from the American Heart Association. Circulation 135:e146-e603

35. Jovanovich A, Chonchol M, Cheung AK, Kaufman JS, Greene T, Roberts WL, Smits G, Kendrick J, HOST Investigators (2012)
Racial differences in markers of mineral metabolism in advanced chronic kidney disease. Clin J Am Soc Nephrol 7:640-647

36. Akhabue E, Montag S, Reis JP, Pool LR, Mehta R, Yancy CW, Zhao L, Wolf M, Gutierrez OM, Carnethon MR, Isakova T (2018) FGF23 (fibroblast growth factor-23) and incident hypertension in young and middle aged adults: the CARDIA study. Hypertension 72:70-76

37. Ishigami J, Taliercio JT, Feldman HI, Srivastava A, Townsend RR, Cohen DL, Horwitz EJ, Rao P, Charleston J, Fink JC, Ricardo AC, Sondheimer J, Chen TK, Wolf M, Isakova T, Appel LJ, Matsushita K, CRIC Study Investigators (2020) Fibroblast Growth Factor 23 and risk of hospitalization with infection in chronic kidney disease: the chronic renal insufficiency cohort (CRIC) study. J Am Soc Nephrol 31:1836-1846

38. Mitsnefes MM, Betoko A, Schneider MF, Salusky IB, Wolf MS, Jüppner H, Warady BA, Furth SL, Portale AA (2018) FGF23 and left ventricular hypertrophy in children with CKD. Clin J Am Soc Nephrol 13:45-52

39. Fyfe-Johnson AL, Alonso A, Selvin E, Bower JK, Pankow JS, Agarwal SK, Lutsey PL (2016) Serum fibroblast growth factor-23 and incident hypertension: the atherosclerosis risk in communities (ARIC) study. J Hypertens 34:1266-1272

40. Ginsberg C, Katz R, Chonchol MB, Bullen AL, Raphael KL, Zhang WR, Ambrosius WT, Bates JT, Neyra JA, Killeen AA, Punzi H, Shlipak MG, Ix JH (2020) The effects of intensive blood pressure lowering on markers of mineral metabolism in persons with CKD in SPRINT. Clin J Am Soc Nephrol 15:852-854

41. Pastor-Arroyo EM, Gehring N, Krudewig C, Costantino S, Bettoni C, Knöpfel T, Sabrautzki S, Lorenz-Depiereux B, Pastor J, Strom TM, Hrabě de Angelis M, Camici GG, Paneni F, Wagner CA, Rubio-Aliaga I (2018) The elevation of circulating fibroblast growth factor 23 without kidney disease does not increase cardiovascular disease risk. Kidney Int 94:49-59

42. Subramanya AR, Ellison DH (2014) Distal convoluted tubule. Clin J Am Soc Nephrol 9:2147-2163

43. Arroyo JP, Ronzaud C, Lagnaz D, Staub O, Gamba G (2011) Aldosterone paradox: diferential regulation of ion transport in distal nephron. Physiology (Bethesda) 26:115-123

44. Sabath E, Meade P, Berkman J, De Los Heros P, Moreno E, Bobadilla NA, Vazquez N, Ellison DH, Gamba G (2004) Pathophysiology of functional mutations of the thiazide-sensitive $\mathrm{Na}-\mathrm{Cl}$ cotransporter in Gitelman disease. Am J Physiol Ren Physiol 287:F195-F203

45. Hadchouel J, Ellison DH, Gamba G (2016) Regulation of renal electrolyte transport by WNK and SPAK-OSR1 kinases. Annu Rev Physiol 78:367-389

46. Pathare G, Foller M, Michael D, Walker B, Hierlmeier M, Mannheim JG, Pichler BJ, Lang F (2012) Enhanced FGF23 serum concentrations and phosphaturia in gene targeted mice expressing WNK-resistant SPAK. Kidney Blood Press Res 36:355364

47. Pathare G, Anderegg M, Albano G, Lang F, Fuster DG (2018) Elevated FGF23 levels in mice lacking the thiazide-sensitive $\mathrm{NaCl}$ cotransporter (NCC). Sci Rep 8:3590

48. Zhang B, Umbach AT, Chen H, Yan J, Fakhri H, Fajol A, Salker MS, Spichtig D, Daryadel A, Wagner CA, Föller M, Lang F (2016) Up-regulation of FGF23 release by aldosterone. Biochem Biophys Res Commun 470:384-390

49. Kwon TH, Frøkiaer J, Fernández-Llama P, Maunsbach AB, Knepper MA, Nielsen S (1999) Altered expression of Na transporters NHE-3, NaPi-II, Na-K-ATPase, BSC-1, and SC in CRF rat kidneys. Am J Phys 277:F257-F270

50. Bazua-Valenti S, Rojas-Vega L, Castaneda-Bueno M, BarreraChimal J, Bautista R, Cervantes-Perez LG, Vazquez N, Plata C, Murillo-de-Ozores AR, Gonzalez-Mariscal L, Ellison DH, Riccardi D, Bobadilla NA, Gamba G (2018) The calcium- 
sensing receptor increases activity of the renal NCC through the WNK4-SPAK pathway. J Am Soc Nephrol 29:1838-1848

51. Koomans HA, Roos JC, Dorhout Mees EJ, Delawi IM (1985) Sodium balance in renal failure. A comparison of patients with normal subjects under extremes of sodium intake. Hypertension 7: 714-721

52. Slatopolsky E (2011) The intact nephron hypothesis: the concept and its implications for phosphate management in CKD-related mineral and bone disorder. Kidney Int 79:S3-S8

53. Schultze RG, Shapiro HS, Bricker NS (1969) Studies on the control of sodium excretion in experimental uremia. J Clin Invest 48: 869-877

54. Hayslett JP, Kashgarian M, Epstein FH (1969) Mechanism of change in the excretion of sodium per nephron when renal mass is reduced. J Clin Invest 48:1002-1006

55. Kim S, Heo NJ, Jung JY, Son MJ, Jang HR, Lee JW, Oh YK, Na KY, Joo KW, Han JS (2010) Changes in the sodium and potassium transporters in the course of chronic renal failure. Nephron Physiol 115:31-41

56. de Seigneux S, Courbebaisse M, Rutkowski JM, Wilhelm-Bals A, Metzger M, Khodo SN, Hasler U, Chehade H, Dizin E, Daryadel A, Stengel B, NephroTest Study Group, Girardin E, Prié D, Wagner CA, Scherer PE, Martin PY, Houillier P, Feraille E (2015) Proteinuria increases plasma phosphate by altering its tubular handling. J Am Soc Nephrol 26:1608-1618

57. Zhou X, Chen K, Lei H, Sun Z (2015) Klotho gene deficiency causes salt-sensitive hypertension via monocyte chemotactic protein-1/CC chemokine receptor 2-mediated inflammation. J Am Soc Nephrol 26:121-132

58. Citterio L, DelliCarpini S, Lupoli S, Brioni E, Simonini M, Fontana S, Zagato L, Messaggio E, Barlassina C, Cusi D, Manunta P, Lanzani C (2020) Klotho gene in human saltsensitive hypertension. Clin J Am Soc Nephrol 15:375-383

59. Friedman DJ, Afkarian M, Tamez H, Bhan I, Isakova T, Wolf M, Ankers E, Ye J, Tonelli M, Zoccali C, Kuro-o M, Moe O, Karumanchi SA, Thadhani R (2009) Klotho variants and chronic hemodialysis mortality. J Bone Miner Res 24:1847-1855

60. Elghoroury EA, Fadel FI, Elshamaa MF, Kandil D, Salah DM, ElSonbaty MM, Farouk H, Raafat M, Nasr S (2018) Klotho G-395A gene polymorphism: impact on progression of end-stage renal disease and development of cardiovascular complications in children on dialysis. Pediatr Nephrol 33:1019-1027

61. Bigazzi R, Zagato L, Lanzani C, Fontana S, Messaggio E, DelliCarpini S, Citterio L, Simonini M, Brioni E, Magnaghi C, Colombo GI, Santini G, Nistri F, Cellai F, Lenti S, Bianchi S, Pertosa GB, Rocchetti MT, Papale M, Mezzolla V, Gesualdo L, Pina Concas M, Campese V, Manunta P (2020) Hypertension in high school students: genetic and environmental factors: the HYGEF study. Hypertension 75:71-78

62. Wan M, Smith C, Shah V, Gullet A, Wells D, Rees L, Shroff R (2013) Fibroblast growth factor 23 and soluble klotho in children with chronic kidney disease. Nephrol Dial Transplant 28:153-161

63. Cano FJ, Freundlich M, Ceballos ML, Rojo AP, Azocar MA, Delgado IO, Ibacache MJ, Delucchi MA, Lillo AM, Irarrázabal CE, Ugarte MF (2014) Longitudinal FGF23 and klotho axis characterization in children treated with chronic peritoneal dialysis. Clin Kidney J 7:457-463

64. Park MY, Herrmann SM, Saad A, Eirin A, Tang H, Lerman A, Textor SC, Lerman LO (2015) Biomarkers of kidney injury and klotho in patients with atherosclerotic renovascular disease. Clin J Am Soc Nephrol 10:443-451

65. South AM, Shaltout HA, Gwathmey TM, Jensen ET, Nixon PA, Diz DI, Chappell MC, Washburn LK (2020) Lower urinary $\alpha$ klotho is associated with lower angiotensin-(1-7) and higher blood pressure in young adults born preterm with very low birthweight. J Clin Hypertens (Greenwich) 22:1033-1040
66. Aizawa H, Saito Y, Nakamura T, Inoue M, Imanari T, Ohyama Y, Matsumura Y, Masuda H, Oba S, Mise N, Kimura K, Hasegawa A, Kurabayashi M, Kuro-o M, Nabeshima Y, Nagai R (1998) Downregulation of the klotho gene in the kidney under sustained circulatory stress in rats. Biochem Biophys Res Commun 249: 865-871

67. Zhou X, Chen K, Wang Y, Schuman M, Lei H, Sun Z (2016) Antiaging gene klotho regulates adrenal CYP11B2 expression and aldosterone synthesis. J Am Soc Nephrol 27:1765-1776

68. Mohammad J, Scanni R, Bestmann L, Hulter HN, Krapf R (2018) A controlled increase in dietary phosphate elevates BP in healthy human subjects. J Am Soc Nephrol 29:2089-2098

69. Dominguez JR, Shlipak MG, Whooley MA, Ix JH (2013) Fractional excretion of phosphorus modifies the association between fibroblast growth factor-23 and outcomes. J Am Soc Nephrol 24:647-654

70. Saglikes Y, Massry SG, Iseki K, Brautbar N, Barndt R, Brunton LL, Buxton IL, Vlachakis N, Campese VM (1985) Effect of phosphate depletion on blood pressure and vascular reactivity to norepinephrine and angiotensin II in the rat. Am J Phys 248:F93-F99

71. Liu P, Bai X, Wang H, Karaplis A, Goltzman D, Miao D (2009) Hypophosphatemia-mediated hypotension in transgenic mice overexpressing human FGF-23. Am J Physiol Heart Circ Physiol 297:H1514-H1520

72. Vered I, Vered Z, Perez JE, Jaffe AS, Whyte MP (1990) Normal left ventricular performance in children with $\mathrm{X}$-linked hypophosphatemic rickets: a Doppler echocardiography study. J Bone Miner Res 5:469-474

73. Davis SV, Olichwier KK, Chakko SC (1988) Reversible depression of myocardial performance in hypophosphatemia. Am J Med Sci 295:183-187

74. Alon US, Monzavi R, Lilien M, Rasoulpour M, Geffner ME, Yadin O (2003) Hypertension in hypophosphatemic ricketsrole of secondary hyperparathyroidism. Pediatr Nephrol 18:155158

75. Hernández-Frías $\mathrm{O}$, Gil-Peña H, Pérez-Roldán JM, GonzálezSanchez S, Ariceta G, Chocrón S, Loza R, de la Cerda Ojeda F, Madariaga L, Vergara I, Fernández-Fernández M, FerrandoMonleón S, Antón-Gamero M, Fernández-Maseda Á, LuisYanes MI, Santos F (2019) Risk of cardiovascular involvement in pediatric patients with X-linked hypophosphatemia. Pediatr Nephrol 34:1077-1086

76. Nehgme R, Fahey JT, Smith C, Carpenter TO (1997) Cardiovascular abnormalities in patients with X-linked hypophosphatemia. J Clin Endocrinol Metab 82:2450-2454

77. Laragh JH, Baer L, Brunner HR, Buhler FR, Sealey JE, Vaughan ED Jr (1972) Renin, angiotensin and aldosterone system in pathogenesis and management of hypertensive vascular disease. Am J Med 52:633-652

78. Santos RA, Simoes e Silva AC, Maric C, Silva DM, Machado RP, de Buhr I, Heringer-Walther S, Pinheiro SV, Lopes MT, Bader M, Mendes EP, Lemos VS, Campagnole-Santos MJ, Schultheiss HP, Speth R, Walther T (2003) Angiotensin-(1-7) is an endogenous ligand for the $\mathrm{G}$ protein-coupled receptor Mas. Proc Natl Acad Sci U S A 100:8258-8263

79. Prieto MC, Gonzalez-Villalobos RA, Botros FT, Martin VL, Pagán J, Satou R, Lara LS, Feng Y, Fernandes FB, Kobori H, Casarini DE, Navar LG (2011) Reciprocal changes in renal ACE/AngII and ACE2/ANG 1-7 are associated with enhanced collecting duct renin in Goldblatt hypertensive rats. Am J Physiol Ren Physiol 300:F749-F755

80. Pi M, Ye R, Han X, Armstrong B, Liu X, Chen Y, Sun Y, Quarles LD (2018) Cardiovascular interactions between fibroblast growth factor-23 and angiotensin II. Sci Rep 8:12398

81. Dai B, David V, Martin A, Huang J, Li H, Jiao Y, Gu W, Quarles LD (2012) A comparative transcriptome analysis identifying 
FGF23 regulated genes in the kidney of a mouse CKD model. PLoS One 7:e44161

82. Hanudel MR, Wesseling-Perry K, Gales B, Campbell V, Ethridge K, Scotti M, Elashoff DA, Alejos J, Reemtsen B, Salusky IB (2016) Effects of acute kidney injury and chronic hypoxemia on fibroblast growth factor 23 levels in pediatric cardiac surgery patients. Pediatr Nephrol 31:661-669

83. Ter Maaten JM, Voors AA, Damman K, van der Meer P, Anker SD, Cleland JG, Dickstein K, Filippatos G, van der Harst P, Hillege HL, Lang CC, Metra M, Navis G, Ng L, Ouwerkerk W, Ponikowski P, Samani NJ, van Veldhuisen DJ, Zannad F, Zwinderman AH, de Borst MH (2018) Fibroblast growth factor 23 is related to profiles indicating volume overload, poor therapy optimization and prognosis in patients with new-onset and worsening heart failure. Int J Cardiol 253:84-90

84. Leifheit-Nestler M, GroßeSiemer R, Flasbart K, Richter B, Kirchhoff F, Ziegler WH, Klintschar M, Becker JU, Erbersdobler A, Aufricht C, Seeman T, Fischer DC, Faul C, Haffner D (2016) Induction of cardiac FGF23/FGFR4 expression is associated with left ventricular hypertrophy in patients with chronic kidney disease. Nephrol Dial Transplant 31:1088-1099

85. Humalda JK, Seiler-Muler S, Kwakernaak AJ, Vervloet MG, Navis G, Fliser D, Heine GH, de Borst MH (2016) Response of fibroblast growth factor 23 to volume interventions in arterial hypertension and diabetic nephropathy. Medicine (Baltimore) 95:e5003

86. Richter M, Lautze HJ, Walther T, Braun T, Kostin S, Kubin T (2015) The failing heart is a major source of circulating FGF23 via oncostatin M receptor activation. J Heart Lung Transplant 34: $1211-1214$

87. Liu Y, Lin Y, Zhang MM, Li XH, Liu YY, Zhao J, Shi L (2020) The relationship of plasma renin, angiotensin, and aldosterone levels to blood pressure variability and target organ damage in children with essential hypertension. BMC Cardiovasc Disord 20:296

88. South AM, Arguelles L, Finer G, Langman CB (2017) Race, obesity, and the renin-angiotensin-aldosterone system: treatment response in children with primary hypertension. Pediatr Nephrol 32:1585-1594

89. Tsuji K, Maeda T, Kawane T, Matsunuma A, Horiuchi N (2010) Leptin stimulates fibroblast growth factor 23 expression in bone and suppresses renal 1alpha,25-dihydroxyvitamin D3 synthesis in leptin-deficient mice. J Bone Miner Res 25:1711-1723

90. Faulkner JL, Bruder-Nascimento T, Belin de Chantemele EJ (2018) The regulation of aldosterone secretion by leptin: implications in obesity-related cardiovascular disease. Curr Opin Nephrol Hypertens 27:63-69

91. Grethen E, Hill KM, Jones R, Cacucci BM, Gupta CE, Acton A, Considine RV, Peacock M (2012) Serum leptin, parathyroid hormone, 1,25-dihydroxyvitamin $\mathrm{D}$, fibroblast growth factor 23 , bone alkaline phosphatase, and sclerostin relationships in obesity. J Clin Endocrinol Metab 97:1655-1662

92. l'Allemand-Jander D (2010) Clinical diagnosis of metabolic and cardiovascular risks in overweight children: early development of chronic diseases in the obese child. Int J Obes 34(suppl 2):S32S36

93. Falkner B, Keith SW, Gidding SS, Langman CB (2017) Fibroblast growth factor-23 is independently associated with cardiac mass in African-American adolescent males. J Am Soc Hypertens 11: 480-487

94. Li YC, Kong J, Wei M, Chen ZF, Liu SQ, Cao LP (2002) 1,25dihydroxyvitamin $\mathrm{D} 3$ is a negative endocrine regulator of the renin-angiotensin system. J Clin Invest 110:229-238

95. Freundlich M, Quiroz Y, Zhang Z, Zhang Y, Bravo Y, Weisinger JR, Li YC, Rodriguez-Iturbe B (2008) Suppression of renin- angiotensin gene expression in the kidney by paricalcitol. Kidney Int 74:1394-1402

96. Czaya B, Seeherunvong W, Singh S, Yanucil C, Ruiz P, Quiroz Y, Grabner A, Katsoufis C, Swaminathan S, Abitbol C, RodriguezIturbe B, Faul C, Freundlich M (2019) Cardioprotective effects of paricalcitol alone and in combination with FGF23 receptor inhibition in chronic renal failure: experimental and clinical studies. Am J Hypertens 32:34-44

97. Bouillon R, Carmeliet G, Verlinden L, van Etten E, Verstuyf A, Luderer HF, Lieben L, Mathieu C, Demay M (2008) Vitamin D and human health: lessons from vitamin $\mathrm{D}$ receptor null mice. Endocr Rev 29:726-776

98. Riera M, Anguiano L, Clotet S, Roca-Ho H, Rebull M, Pascual J, Soler MJ (2016) Paricalcitol modulates ACE2 shedding and renal ADAM17 in NOD mice beyond proteinuria. Am J Physiol Ren Physiol 310:F534-F546

99. Yoon HE, Ghee JY, Piao S, Song JH, Han DH, Kim S, Ohashi N, Kobori H, Kuro-o M, Yang CW (2011) Angiotensin II blockade upregulates the expression of klotho, the anti-ageing gene, in an experimental model of chronic cyclosporine nephropathy. Nephrol Dial Transplant 26:800-813

100. Zhou L, Mo H, Miao J, Zhou D, Tan RJ, Hou FF, Liu Y (2015) Klotho ameliorates kidney injury and fibrosis and normalizes blood pressure by targeting the renin-angiotensin system. Am J Pathol 185:3211-3223

101. de Borst MH, Vervloet MG, ter Wee PM, Navis G (2011) Cross talk between the renin-angiotensin-aldosterone system and vitamin D-FGF-23-klotho in chronic kidney disease. J Am Soc Nephrol 22:1603-1609

102. Leyvraz M, Chatelan A, da Costa BR, Taffé P, Paradis G, Bovet P, Bochud M, Chiolero A (2018) Sodium intake and blood pressure in children and adolescents: a systematic review and meta-analysis of experimental and observational studies. Int J Epidemiol 47: $1796-1810$

103. Humalda JK, Lambers Heerspink HJ, Kwakernaak AJ, Kwakernaak AJ, Slagman MC, Waanders F, Vervloet MG, Ter Wee PM, Navis G, de Borst MH, NIGRAM Consortium (2015) Fibroblast growth factor 23 and the antiproteinuric response to dietary sodium restriction during renin-angiotensin-aldosterone system blockade. Am J Kidney Dis 65:259-266

104. Baia LC, Humalda JK, Vervloet MG, Navis G, Bakker SJ, de Borst MH, NIGRAM Consortium (2013) Fibroblast growth factor 23 and cardiovascular mortality after kidney transplantation. Clin J Am Soc Nephrol 8:1968-1978

105. Humalda JK, Riphagen IJ, Assa S, Hummel YM, Westerhuis R, Vervloet MG, Voors AA, Navis G, Franssen CF, de Borst MH, NIGRAM Consortium (2016) Fibroblast growth factor 23 correlates with volume status in haemodialysis patients and is not reduced by haemodialysis. Nephrol Dial Transplant 31:1494-1501

106. Hu JW, Wang Y, Chu C, Mu JJ (2018) Effect of salt intervention on serum levels of fibroblast growth factor 23 (FGF23) in Chinese adults: an intervention study. Med Sci Monit 24:1948-1954

107. Isakova T, Barchi-Chung A, Enfield G, Smith K, Vargas G, Houston J, Xie H, Wahl P, Schiavenato E, Dosch A, Gutiérrez OM, Diego J, Lenz O, Contreras G, Mendez A, Weiner RB, Wolf M (2013) Effects of dietary phosphate restriction and phosphate binders on FGF23 levels in CKD. Clin J Am Soc Nephrol 8:10091018

108. Block GA, Wheeler DC, Persky MS, Kestenbaum B, Ketteler M, Spiegel DM, Allison MA, Asplin J, Smits G, Hoofnagle AN, Kooienga L, Thadhani R, Mannstadt M, Wolf M, Chertow GM (2012) Effects of phosphate binders in moderate CKD. J Am Soc Nephrol 23:1407-1415

109. Sinha AD, Agarwal R (2016) Thiazides are useful agents in CKD. J Am Soc Hypertens 10:288-289 
110. Blowey DL (2016) Diuretics in the treatment of hypertension. Pediatr Nephrol 31:2223-2233

111. Thomas L, Xue J, Murali SK, Fenton RA, Dominguez Rieg JA, Rieg T (2019) Pharmacological Npt2a inhibition causes phosphaturia and reduces plasma phosphate in mice with normal and reduced kidney function. J Am Soc Nephrol 30:2128-2139

112. de Jong MA, Mirkovic K, Mencke R, Hoenderop JG, Bindels RJ, Vervloet MG, Hillebrands JL, van den Born J, Navis G, de Borst MH, NIGRAM Consortium (2017) NIGRAM consortium. Fibroblast growth factor 23 modifies the pharmacological effects of angiotensin receptor blockade in experimental renal fibrosis. Nephrol Dial Transplant 32:73-80

113. Yilmaz MI, Sonmez A, Saglam M, Kurt YG, Unal HU, Karaman M, Gok M, Cetinkaya H, Eyileten T, Oguz Y, Vural A, Mallamaci F, Zoccali C (2014) Ramipril lowers plasma FGF-23 in patients with diabetic nephropathy. Am J Nephrol 40:208-214

114. Lundberg S, Qureshi AR, Olivecrona S, Gunnarsson I, Jacobson SH, Larsson TE (2012) FGF23, albuminuria, and disease progression in patients with chronic IgA nephropathy. Clin J Am Soc Nephrol 7:727-734

115. Hoffmann M, Kleine-Weber H, Schroeder S, Krüger N, Herrler T, Erichsen S, Schiergens TS, Herrler G, Wu NH, Nitsche A, Müller MA, Drosten C, Pöhlmann S (2020) SARS-CoV-2 cell entry depends on ACE2 and TMPRSS2 and is blocked by a clinically proven protease inhibitor. Cell 181:271-280.e8

116. Pirola CJ, Sookoian S (2020) Estimation of renin-angiotensinaldosterone-system (RAAS)-inhibitor effect on COVID-19 outcome: a meta-analysis. J Inf Secur 81:276-281

117. Danser AHJ, Epstein M, Batlle D (2020) Renin-angiotensin system blockers and the COVID-19 pandemic: at present there is no evidence to abandon renin-angiotensin system blockers. Hypertension 75:1382-1385

118. Sparks MA, South A, Welling P, Luther JM, Cohen J, Byrd JB, Burrell LM, Batlle D, Tomlinson L, Bhalla V, Rheault MN, Soler MJ, Swaminathan S, Hiremath S (2020) Sound science before quick judgement regarding RAS blockade in COVID-19. Clin J Am Soc Nephrol 15:714-716

119. Wysocki J, Ye M, Rodriguez E, Barrios C, Evora K, Schuster M, Loibner H, Brosnihan KB, Ferrario CM, Penninger JM, Batlle D (2010) Targeting the degradation of angiotensin II with recombinant angiotensin-converting enzyme 2: prevention of angiotensin II-dependent hypertension. Hypertension 55:90-98

120. Hemnes AR, Rathinasabapathy A, Austin EA, Brittain EL, Carrier EJ, Chen X, Fessel JP, Fike CD, Fong P, Fortune N, Gerszten RE, Johnson JA, Kaplowitz M, Newman JH, Piana R, Pugh ME, Rice TW, Robbins IM, Wheeler L, Yu C, Loyd JE, West J (2018) A potential therapeutic role for angiotensin-converting enzyme 2 in human pulmonary arterial hypertension. Eur Respir J 51:1702638

121. Li JS, Flynn JT, Portman R, Davis I, Ogawa M, Shi H, Pressler ML (2010) The efficacy and safety of the novel aldosterone antagonist eplerenone in children with hypertension: a randomized, double-blind, dose-response study. J Pediatr 157:282-287

122. Seeherunvong W, Abitbol CL, Chandar J, Zilleruelo G, Freundlich M (2009) Vitamin D insufficiency and deficiency in children with early chronic kidney disease. J Pediatr 154:906-911

123. Schmitz KJ, Skinner HG, Bautista LE, Fingerlin TE, Langefeld CD, Hicks PJ, Haffner SM, Bryer-Ash M, Wagenknecht LE, Bowden DW, Norris JM, Engelman CD (2009) Association of 25-hydroxyvitamin D with blood pressure in predominantly 25hydroxyvitamin D deficient Hispanic and African Americans. Am J Hypertens 22:867-870

124. Ismail NA, Kamaruddin NA, Azhar Shah S, Sukor N (2020) The effect of vitamin D treatment on clinical and biochemical outcomes of primary aldosteronism. Clin Endocrinol 92:509-517

125. Wesseling-Perry K, Pereira RC, Sahney S, Gales B, Wang HJ, Elashoff R, Jüppner H, Salusky IB (2011) Calcitriol and doxercalciferol are equivalent in controlling bone turnover, suppressing parathyroid hormone, and increasing fibroblast growth factor-23 in secondary hyperparathyroidism. Kidney Int 79:112119

126. Lundqvist J, Norlin M, Wikvall K (2010) 1alpha,25Dihydroxyvitamin D3 affects hormone production and expression of steroidogenic enzymes in human adrenocortical NCIH295R cells. Biochim Biophys Acta 1801:1056-1062

127. Ritter CS, Zhang S, Delmez J, Finch JL, Slatopolsky E (2015) Differential expression and regulation of klotho by paricalcitol in the kidney, parathyroid, and aorta of uremic rats. Kidney Int 87: $1141-1152$

128. Arenas Morales AJ, DeFreitas MJ, Katsoufis CP, Seeherunvong W, Chandar J, Zilleruelo G, Freundlich M, Abitbol CL (2019) Cinacalcet as rescue therapy for refractory hyperparathyroidism in young children with advanced chronic kidney disease. Pediatr Nephrol 34:129-135

129. Bacchetta J, Schmitt CP, Ariceta G, Bakkaloglu SA, Groothoff J, Wan M, Vervloet M, Shroff R, Haffner D, European Society for Paediatric Nephrology and the Chronic Kidney Disease-Mineral and Bone Disorders and Dialysis Working Group of the ERAEDTA (2020) Cinacalcet use in paediatric dialysis: a position statement from the European Society for Paediatric Nephrology and the Chronic Kidney Disease-Mineral and Bone Disorders Working Group of the ERA-EDTA. Nephrol Dial Transplant 35: 47-64

130. Wolf M, Block GA, Chertow GM, Cooper K, Fouqueray B, Moe SM, Sun Y, Tomlin H, Vervloet M, Oberbauer R (2019) Effects of etelcalcetide on fibroblast growth factor 23 in patients with secondary hyperparathyroidism receiving hemodialysis. Clin Kidney J 13:75-84

131. Silverstein DM, Kher KK, Moudgil A, Khurana M, Wilcox J, Moylan K (2008) Cinacalcet is efficacious in pediatric dialysis patients. Pediatr Nephrol 23:1817-1822

132. Chang TI, Abdalla S, London GM, Block GA, Correa-Rotter R, Drüeke TB, Floege J, Herzog CA, Mahaffey KW, Moe SM, Parfrey PS, Wheeler DC, Dehmel B, Goodman WG, Chertow GM (2016) The effects of cinacalcet on blood pressure, mortality and cardiovascular endpoints in the EVOLVE trial. J Hum Hypertens 30:204-209

133. Shalhoub V, Shatzen EM, Ward SC, Davis J, Stevens J, Bi V, Renshaw L, Hawkins N, Wang W, Chen C, Tsai MM, Cattley RC, Wronski TJ, Xia X, Li X, Henley C, Eschenberg M, Richards WG (2012) FGF23 neutralization improves chronic kidney disease-associated hyperparathyroidism yet increases mortality. J Clin Invest 122:2543-2553

134. Carpenter TO, Whyte MP, Imel EA, Boot AM, Högler W, Linglart A, Padidela R, Van’t Hoff W, Mao M, Chen CY, Skrinar A, Kakkis E, San Martin J, Portale AA (2018) Burosumab therapy in children with X-linked hypophosphatemia. N Engl J Med 378:1987-1998

135. Shroff R, Aitkenhead H, Costa N, Trivelli A, Litwin M, Picca S, Anarat A, Sallay P, Ozaltin F, Zurowska A, Jankauskiene A, Montini G, Charbit M, Schaefer F, Wühl E, ESCAPE Trial Group (2016) Normal 25-hydroxyvitamin D levels are associated with less proteinuria and attenuate renal failure progression in children with CKD. J Am Soc Nephrol 27:314-322

136. Hum JM, O’Bryan LM, Tatiparthi AK, Cass TA, Clinkenbeard EL, Cramer MS, Bhaskaran M, Johnson RL, Wilson JM, Smith RC, White KE (2017) Chronic hyperphosphatemia and vascular calcification are reduced by stable delivery of soluble klotho. J Am Soc Nephrol 28:1162-1174

137. Franklin AD, Saqibuddin J, Stephens K, Birkett R, Marsden L, Ernst LM, Mestan KK (2019) Cord blood alpha klotho is decreased in small for gestational age preterm infants with placental lesions of accelerated aging. Placenta 87:1-7 
138. Abitbol C, Rodriguez M (2012) The long-term renal and cardiovascular consequences of prematurity. Nat Rev Nephrol 8:265274

139. DeFreitas MJ, Mathur D, Seeherunvong W, Cano T, Katsoufis CP, Duara S, Yasin S, Zilleruelo G, Rodriguez MM, Abitbol CL (2017) Umbilical artery histomorphometry: a link between the intrauterine environment and kidney development. J Dev Orig Health Dis 8:349-356

140. South AM, Nixon PA, Chappell MC, Diz DI, Russell GB, Jensen ET, Shaltout HA, O'Shea TM, Washburn LK (2018) Association between preterm birth and the renin-angiotensin system in adolescence: influence of sex and obesity. J Hypertens 36:2092-2101

141. Ali MF, Venkatarayappa SKB, Benny M, Rojas C, Yousefi K, Shehadeh LA, Kulandavelu S, Sharma M, Da Silva N, Freundlich
M, Abitbol CL, DeFreitas MJ, Young KC (2020) Effects of klotho supplementation on hyperoxia-induced renal injury in a rodent model of postnatal nephrogenesis. Pediatr Res 88:565-570

142. Batlahally S, Franklin A, Damianos A, Huang J, Chen P, Sharma M, Duara J, Keerthy D, Zambrano R, Shehadeh LA, Martinez EC, DeFreitas MJ, Kulandavelu S, Abitbol CL, Freundlich M, Kanashiro-Takeuchi RM, Schmidt A, Benny M, Wu S, Mestan KK, Young KC (2020) Soluble klotho, a biomarker and therapeutic strategy to reduce bronchopulmonary dysplasia and pulmonary hypertension in preterm infants. Sci Rep 10:12368

Publisher's note Springer Nature remains neutral with regard to jurisdictional claims in published maps and institutional affiliations. 